\title{
Current-Mode Third-Order Quadrature Oscillator Using CDTAs
}

\author{
Jiun-Wei Horng \\ Department of Electronic Engineering, Chung Yuan Christian University, Chung-Li 32023, Taiwan \\ Correspondence should be addressed to Jiun-Wei Horng, jwhorng@cycu.edu.tw
}

Received 27 May 2009; Revised 18 August 2009; Accepted 8 September 2009

Recommended by Yalin Lu

This paper describes a current-mode third-order quadrature oscillator based on current differencing transconductance amplifiers (CDTAs). Outputs of two current-mode sinusoids with $90^{\circ}$ phase difference are available in the quadrature oscillator circuit. The oscillation condition and oscillation frequency are orthogonal controllable. The proposed circuit employs only grounded capacitors and is ideal for integration. Simulation results are included to confirm the theoretical analysis.

Copyright ( $) 2009$ Jiun-Wei Horng. This is an open access article distributed under the Creative Commons Attribution License, which permits unrestricted use, distribution, and reproduction in any medium, provided the original work is properly cited.

\section{Introduction}

Various new current-mode active building blocks have received considerable attentions owing to their larger dynamic range and wider bandwidth with respect to operational amplifier-based circuits. As a result, current-mode active components have been increasingly used to realize active filters, sinusoidal oscillators, and immittances.

Quadrature oscillator is used because the circuit provides two sinusoids with $90^{\circ}$ phase difference, as, for example, in telecommunications for quadrature mixers and singlesideband generators or for measurement purposes in vector generators or selective voltmeters. Therefore, quadrature oscillators constitute an important unit in many communication and instrumentation systems [1-17]. Two-integrator loop technique was developed to realize quadrature oscillators by using operational amplifiers or transconductance elements in [1, 2]. Holzel [3] proposed a method for realizing quadrature oscillator consists of two allpass filters and an inverter using operational amplifiers. Keskin et al. $[15,17]$ proposed two quadrature oscillators that were designed out by the method in [3] using current differencing buffered amplifiers (CDBAs) or current differencing transconductance amplifiers (CDTAs). Ahmed et al. [4] proposed two quadrature oscillator circuits that were realized base on the allpass filters and the noninverting integrators as building blocks using operational transconductance amplifiers (OTAs). This method was also used in [16] to obtain a quadrature oscillator using CDBAs. Soliman [6] describes several quadrature oscillator circuits based on the modification of two-integrator loop technique using current conveyors. Because the high-order network has high accuracy and high-quality factor, it gives good frequency response with low distortion [9-12]. Prommee and Dejhan [9] proposed two third-order quadrature oscillators using OTAs. Horng et al. [10, 11] proposed four voltage-mode third-order quadrature oscillator circuits; each circuit uses three second-generation current conveyors (CCIIs). Maheshwari and Khan [12] proposed a current-mode third-order quadrature oscillator using four CCIIs.

In 2003, a new current-mode active element that is called current differencing transconductance amplifier (CDTA) was introduced [18]. Owing to the current conveying property, the CDTA is one of the modifications of the current conveyor (CC). Many applications in the design of active filter [19] and multiphase sinusoidal oscillator [20] using CDTAs as active elements have received considerable attention. A second-order current-mode quadrature oscillator consists of two CDTAs, four resistors, and two capacitors was presented in [17]. However, the capacitors used in this circuit are connected to the input terminals of the CDTAs. Since the input terminals of CDTA have parasitic resistances [20], this quadrature oscillator is not ideal for high-frequency applications. In 2006, Biolek et al. proposed a second-order current-mode quadrature oscillator based on 


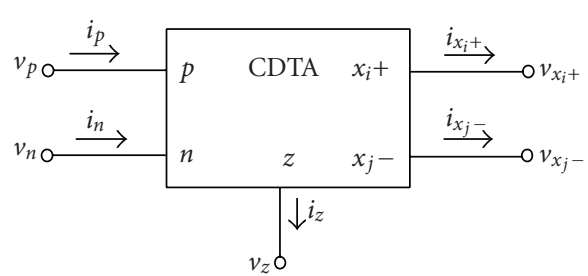

(a)

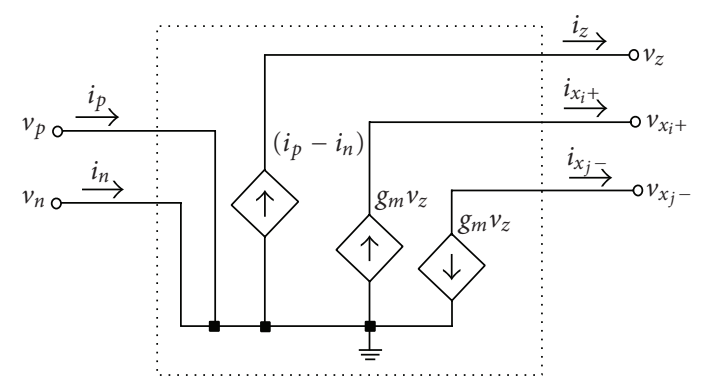

(b)

Figure 1: (a) Circuit symbol of CDTA. (b) Equivalent circuit of CDTA.

two-integrator loop technique [21]. The main disadvantage of this oscillator is that there is no control on the condition of oscillation.

In this paper, a CDTAs-based current-mode third-order quadrature oscillator circuit is presented. The oscillation condition and oscillation frequency of the proposed quadrature oscillator are orthogonal controllable. The proposed quadrature oscillator uses only grounded capacitors. The use of only grounded capacitors is especially interest from the fabrication point of view [22].

\section{Proposed Circuit}

The circuit symbol and the equivalent circuit of the CDTA are shown in Figure 1. The terminal characteristic of the CDTA can be described by the following equations [18]:

$$
v_{p}=v_{n}=0, \quad i_{z}=i_{p}-i_{n}, \quad i_{x}= \pm g_{m} v_{z}=g_{m} Z_{z} i_{z}
$$

where $p$ and $n$ are input terminals, $z$ and $x \pm$ are output terminals, $g_{m}$ is the transconductance gain, and $Z_{z}$ is external impedance connected at the $z$ terminal. According to the above equation and equivalent circuit of Figure 1(b), the current flowing out of the terminal $z\left(i_{z}\right)$ is a difference between the currents through the terminals $p$ and $n\left(i_{p}-i_{n}\right)$. The voltage drop at the terminal $z$ is transferred to the currents at the terminal $x_{i}+$ by the transconductance gain $\left(g_{m}\right)$, which is electrically controllable by an external bias voltage. These currents that are copied to a general number of output current terminals $x_{j}$ - are equal in magnitude but flow in opposite directions. A possible CMOS-based CDTA circuit realization is given in Figure 2 [17].
The CDTAs-based third-order quadrature oscillator is shown in Figure 3. The characteristic equation of the circuit in Figure 3 can be expressed as

$$
\begin{aligned}
& s^{3} C_{1} C_{2} C_{3}+s^{2} C_{3}\left(C_{1} g_{m 2}+C_{2} g_{m 1}\right)+s C_{3} g_{m 1} g_{m 2} \\
& +g_{m 1} g_{m 2} g_{m 3}=0 .
\end{aligned}
$$

The oscillation condition and oscillation frequency can be obtained as

$$
\begin{gathered}
g_{m 3}=\frac{C_{3}\left(C_{1} g_{m 2}+C_{2} g_{m 1}\right)}{C_{1} C_{2}}, \\
\omega_{o}=\sqrt{\frac{g_{m 1} g_{m 2}}{C_{1} C_{2}}} .
\end{gathered}
$$

From (3) and (4), the oscillation frequency can be controlled by $g_{m 1}$ or $g_{m 2}$. The oscillation condition can be independently controlled by $g_{m 3}$. From Figure 3 , the current transfer function from $I_{o 2}$ to $I_{o 1}$ is

$$
\frac{I_{o 2}(s)}{I_{o 1}(s)}=-\frac{g_{m 3}}{s C_{3}} .
$$

Under sinusoidal steady state, (5) becomes

$$
\frac{I_{o 2}(j \omega)}{I_{o 1}(j \omega)}=\frac{g_{m 3}}{\omega C_{3}} e^{j 90^{\circ}} .
$$

The phase difference, $\phi$, between $I_{o 2}$ and $I_{o 1}$ is

$$
\phi=90^{\circ}
$$

ensuring the voltages $I_{o 2}$ and $I_{o 1}$ to be in quadrature.

The proposed quadrature oscillator employs only grounded capacitors. The use of grounded capacitors is particularly attractive for integrated circuit implementation [22]. From (6), the magnitude of $I_{o 2}$ and $I_{o 1}$ need not the same. For the applications need equal magnitude quadrature outputs, another amplifying circuits are needed.

\section{Nonideal Effects}

Taking the nonidealities of the CDTA into account, Figure 4 shows the simplified equivalent circuit that is used to represent the nonideal CDTA [20]. In the figure, $\alpha_{p}=1-\varepsilon_{p}$ and $\varepsilon_{p}\left(\left|\varepsilon_{p}\right| \ll 1\right)$ is the current tracking error from the $p$ terminal to the $z$ terminal of the CDTA, $\alpha_{n}=1-\varepsilon_{n}$ and $\varepsilon_{n}\left(\left|\varepsilon_{n}\right| \ll 1\right)$ is the current tracking error from the $n$ terminal to the $z$ terminal of the CDTA, and $\beta=1-\varepsilon_{i}$ and $\varepsilon_{i}\left(\left|\varepsilon_{i}\right| \ll 1\right)$ is the output transconductance tracking error from the $z$ terminal to $x$ terminal of the CDTA. Moreover, there are parasitic resistances $\left(R_{p}\right.$ and $\left.R_{n}\right)$ at terminals $p$ and $n$ and parasitic resistances and capacitances $\left(R_{z}, C_{z}\right.$ and $R_{x}$, $C_{x}$ ) from terminals $z$ and $x$ to ground. Reanalysing of the proposed quadrature oscillator in Figure 3 using the nonideal CDTA model and assuming that the operation oscillation frequencies, $\omega$, are very much smaller than $1 / C_{x} R_{n}$ or $1 / C_{x} R_{p}$ and the parasitic resistances at the $x$ terminals are very much greater than the parasitic resistances at $p$ or $n$ terminals of CDTAs, the characteristic equation of Figure 3 becomes 


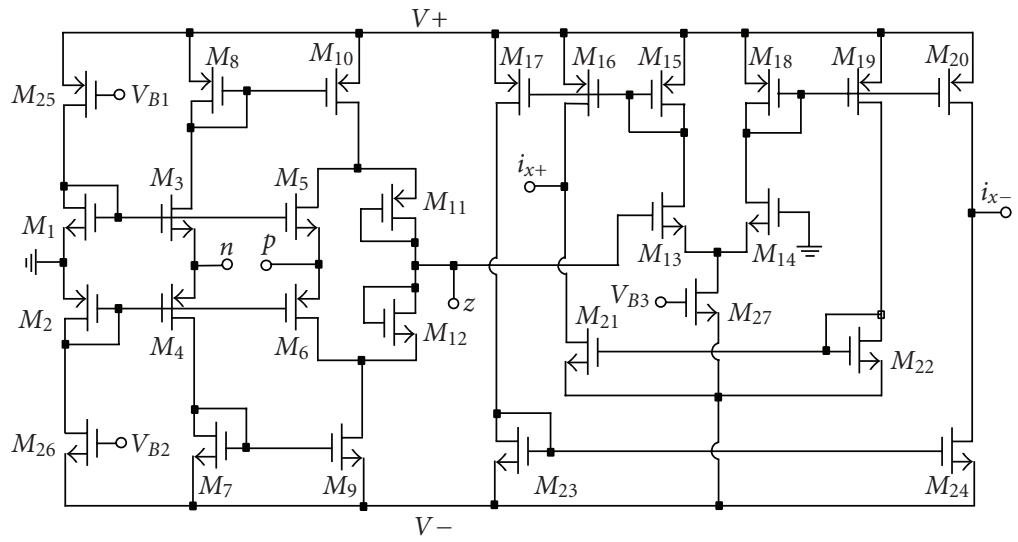

Figure 2: CMOS-based CDTA.

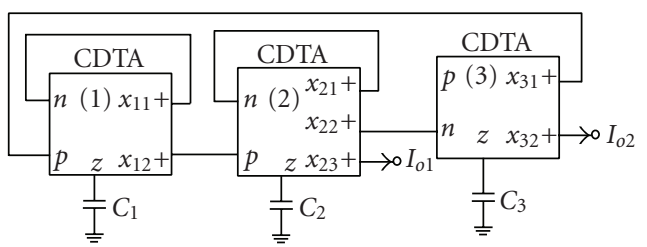

FIGURE 3: The proposed current-mode quadrature oscillator.

$$
\begin{gathered}
s^{3} C_{1}^{\prime} C_{2}^{\prime} C_{3}^{\prime}+s^{2}\left[C_{1}^{\prime} C_{3}^{\prime}\left(g_{m 2} \alpha_{n 2} \beta_{21}+G_{z 2}\right)\right. \\
\left.+C_{2}^{\prime} C_{3}^{\prime}\left(g_{m 1} \alpha_{n 1} \beta_{11}+G_{z 1}\right)+C_{1}^{\prime} C_{2}^{\prime} G_{z 3}\right] \\
+s\left[C _ { 3 } ^ { \prime } \left(g_{m 1} g_{m 2} \alpha_{n 1} \alpha_{n 2} \beta_{11} \beta_{21}+g_{m 1} G_{z 2} \alpha_{n 1} \beta_{11}\right.\right. \\
\left.+g_{m 2} G_{z 1} \alpha_{n 2} \beta_{21}+G_{z 1} G_{z 2}\right) \\
+C_{1}^{\prime}\left(g_{m 2} G_{z 3} \alpha_{n 2} \beta_{21}+G_{z 2} G_{z 3}\right) \\
\left.+C_{2}^{\prime}\left(g_{m 1} G_{z 3} \alpha_{n 1} \beta_{11}+G_{z 1} G_{z 3}\right)\right] \\
+g_{m 1} g_{m 2}\left(g_{m 3} \alpha_{p 1} \alpha_{p 2} \alpha_{n 3} \beta_{12} \beta_{22} \beta_{31}+G_{z 3} \alpha_{n 1} \alpha_{n 2} \beta_{11} \beta_{21}\right) \\
+G_{z 3}\left(g_{m 1} G_{z 2} \alpha_{n 1} \beta_{11}+g_{m 2} G_{z 1} \alpha_{n 2} \beta_{21}+G_{z 1} G_{z 2}\right)=0,
\end{gathered}
$$

where $C_{1}^{\prime}=C_{1}+C_{z 1}, C_{2}^{\prime}=C_{2}+C_{z 2}, C_{3}^{\prime}=C_{3}+C_{z 3}$.

The modified oscillation condition and oscillation frequency are

$$
\begin{gathered}
\frac{g_{m 1} g_{m 2} \mathcal{H}+G_{z 3} \mathscr{B}}{C_{1}^{\prime} C_{3}^{\prime} \mathfrak{C}+C_{2}^{\prime} C_{3}^{\prime} \mathscr{D}+C_{1}^{\prime} C_{2}^{\prime} G_{z 3}} \\
=\frac{C_{3}^{\prime} \mathscr{E}+C_{1}^{\prime} \mathfrak{F}+C_{2}^{\prime} \mathscr{H}}{C_{1}^{\prime} C_{2}^{\prime} C_{3}^{\prime}}, \\
\omega_{o}=\sqrt{\frac{C_{3}^{\prime} \mathscr{E}+C_{1}^{\prime} \mathscr{F}+C_{2}^{\prime} \mathscr{H}}{C_{1}^{\prime} C_{2}^{\prime} C_{3}^{\prime}}},
\end{gathered}
$$

where $\mathcal{A}=\left(g_{m 3} \alpha_{p 1} \alpha_{p 2} \alpha_{n 3} \beta_{12} \beta_{22} \beta_{31}+G_{z 3} \alpha_{n 1} \alpha_{n 2} \beta_{11} \beta_{21}\right), \mathscr{B}=$ $\left(g_{m 1} G_{z 2} \alpha_{n 1} \beta_{11}+g_{m 2} G_{z 1} \alpha_{n 2} \beta_{21}+G_{z 1} G_{z 2}\right), \boldsymbol{e}=\left(g_{m 2} \alpha_{n 2} \beta_{21}+\right.$ $\left.G_{z 2}\right), \mathscr{D}=\left(g_{m 1} \alpha_{n 1} \beta_{11}+G_{z 1}\right), \boldsymbol{E}=\left(g_{m 1} g_{m 2} \alpha_{n 1} \alpha_{n 2} \beta_{11} \beta_{21}+\right.$ $\left.g_{m 1} G_{z 2} \alpha_{n 1} \beta_{11}+g_{m 2} G_{z 1} \alpha_{n 2} \beta_{21}+G_{z 1} G_{z 2}\right), \tilde{F}=\left(g_{m 2} G_{z 3} \alpha_{n 2} \beta_{21}+\right.$ $\left.G_{z 2} G_{z 3}\right)$, and $\mathscr{H}=\left(g_{m 1} G_{z 3} \alpha_{n 1} \beta_{11}+G_{z 1} G_{z 3}\right)$.

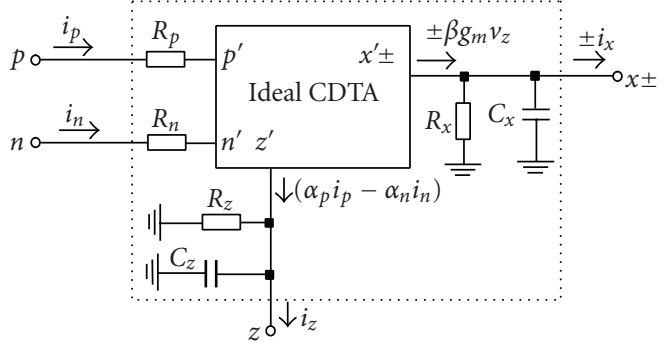

Figure 4: The nonideal CDTA.

TABLE 1: Aspect ratios of the MOS in Figure 2.

\begin{tabular}{lc}
\hline MOS transistors & Aspect ratio (W/L) \\
\hline$M_{1}, M_{3}, M_{5}, M_{7}, M_{9}, M_{12}$, & $27 / 1.8$ \\
$M_{21}, M_{22}, M_{23}, M_{24}, M_{26}$ & \\
\hline$M_{2}, M_{4}, M_{6}, M_{8}, M_{10}, M_{11}$ & $72 / 1.8$ \\
$M_{13}, M_{14}, M_{25}, M_{27}$ & \\
\hline$M_{15}, M_{16}, M_{17}, M_{18}, M_{19}, M_{20}$ & $63 / 1.8$
\end{tabular}

Because the values of $\alpha$ and $\beta$ are slightly less than unity [23], the parasitic conductances $\left(G_{z} s\right)$ at the $z$ terminals of CDTAs are not zero and the capacitances $C_{1}^{\prime}, C_{2}^{\prime}$, and $C_{3}^{\prime}$ are greater than $C_{1}, C_{2}$, and $C_{3}$, respectively. From (9) and (10), the oscillation condition and oscillation frequency are deviated from the ideal cases. Therefore, to compensate this effect, we can slightly adjust the $g_{m 1}$ or $g_{m 2}$ values. The oscillation condition still can be independently controlled by $g_{m 3}$. The active and passive sensitivities of the quadrature oscillator are all low and obtained as

$$
S_{\alpha_{n 1}, \alpha_{n 2}, \beta_{11}, \beta_{21}}^{\omega_{o}} \cong \frac{1}{2} ; \quad S_{g_{m 1}, g_{m 2}}^{\omega_{o}} \cong-S_{C_{1}^{\prime}, C_{2}^{\prime}}^{\omega_{o}} \cong \frac{1}{2} ; \quad S_{C_{3}^{\prime}}^{\omega_{o}} \cong 0 .
$$

\section{Simulation Results}

The quadrature oscillators were simulated using HSPICE. The CMOS CDTA implementation is shown in Figure 2 (using $0.18 \mu \mathrm{m}$ MOSFET from TSMC). The aspect ratios 


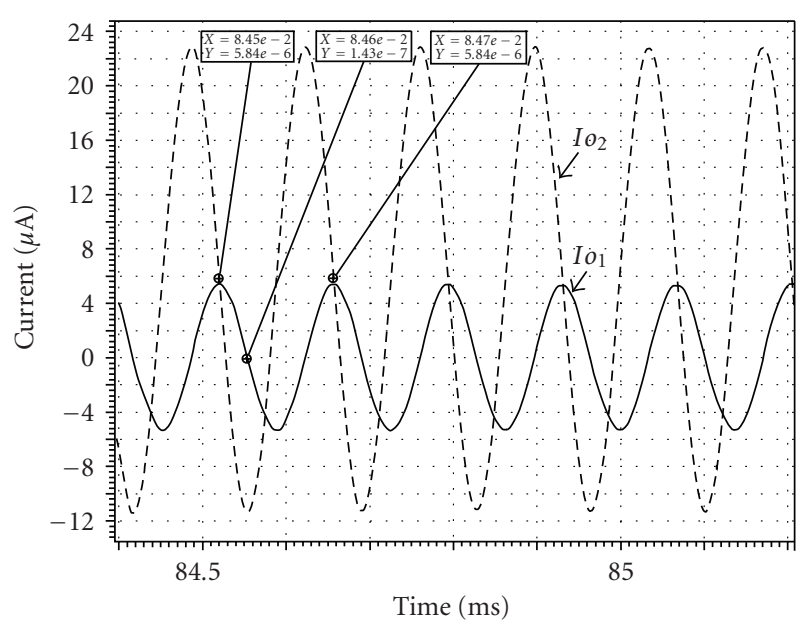

Figure 5: The simulated current-mode quadrature output waveforms of Figure 3.

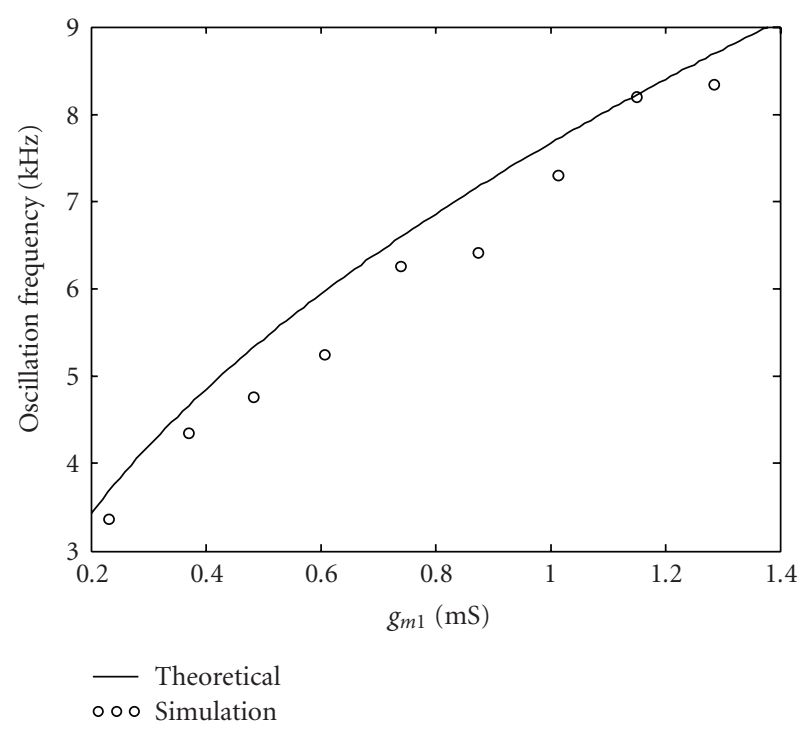

FIGURE 6: Simulation results of the oscillation frequency of Figure 3, which is obtained by varying the value of the transconductance $g_{m 1}$.

of the MOS transistors were chosen as in Table 1. The multiple current outputs can be easily implemented by adding output branches. Figure 5 represents the currentmode quadrature sinusoidal output waveforms of Figure 3 with $C_{1}=C_{2}=C_{3}=10 \mathrm{nF}, g_{m 1}=1.015 \mathrm{mS}, g_{m 2}=$ $232 \mu \mathrm{S}$, and $g_{m 3}=1.35 \mathrm{mS}$ where $g_{m 3}$ was designed to be larger than the theoretical value to ensure that the oscillations will start. The bias voltages are $V_{B 1}=0.7 \mathrm{~V}, V_{B 2}=$ $-0.7 \mathrm{~V}, V+=1.25 \mathrm{~V}$, and $V-=-1.25 \mathrm{~V}$. The power dissipation is $3.9486 \mathrm{~mW}$. The results of the $I_{o 1}$ and $I_{o 2}$ total harmonic distortion analysis are summarized in Tables 2 and 3 , respectively. Figure 6 shows the simulation results of the oscillation frequencies of Figure 3 by varying the value of the transconductance $g_{m 1}$ with $C_{1}=C_{2}=C_{3}=10 \mathrm{nF}$, $g_{m 2}=232 \mu \mathrm{S}$, and $g_{m 3}$ was varied with $g_{m 1}$ by (3) to ensures that the oscillations will start.
TABLE 2: Total harmonic distortion analysis of $I_{o 1}$ in Figure 3.

\begin{tabular}{lccc}
\hline $\begin{array}{c}\text { Harmonic } \\
\text { no }\end{array}$ & $\begin{array}{c}\text { Frequency } \\
(\mathrm{hz})\end{array}$ & $\begin{array}{c}\text { Fourier } \\
\text { component }\end{array}$ & $\begin{array}{c}\text { Phase } \\
(\mathrm{deg})\end{array}$ \\
\hline 1 & $7.3000 \mathrm{k}$ & $5.3864 \mathrm{u}$ & 166.4101 \\
2 & $14.6000 \mathrm{k}$ & $103.5180 \mathrm{n}$ & -107.3535 \\
3 & $21.9000 \mathrm{k}$ & $7.0925 \mathrm{n}$ & -173.5386 \\
4 & $29.2000 \mathrm{k}$ & $50.7076 \mathrm{n}$ & -155.1803 \\
5 & $36.5000 \mathrm{k}$ & $51.3941 \mathrm{n}$ & 106.5849 \\
6 & $43.8000 \mathrm{k}$ & $32.4016 \mathrm{n}$ & -168.3840 \\
7 & $51.1000 \mathrm{k}$ & $41.8477 \mathrm{n}$ & 73.1948 \\
8 & $58.4000 \mathrm{k}$ & $8.4629 \mathrm{n}$ & 120.4927 \\
9 & $65.7000 \mathrm{k}$ & $18.1728 \mathrm{n}$ & 35.0011 \\
\hline \multicolumn{4}{c}{ dc component $=-2.329 \mathrm{D}-09$} \\
\hline
\end{tabular}

TABLE 3: Total harmonic distortion analysis of $I_{o 2}$ in Figure 3.

\begin{tabular}{lccc}
\hline $\begin{array}{c}\text { Harmonic } \\
\text { no }\end{array}$ & $\begin{array}{c}\text { Frequency } \\
(\mathrm{hz})\end{array}$ & $\begin{array}{c}\text { Fourier } \\
\text { component }\end{array}$ & $\begin{array}{c}\text { Phase } \\
(\mathrm{deg})\end{array}$ \\
\hline 1 & $7.3000 \mathrm{k}$ & $17.1387 \mathrm{u}$ & -103.6257 \\
2 & $14.6000 \mathrm{k}$ & $166.8692 \mathrm{n}$ & -16.1700 \\
3 & $21.9000 \mathrm{k}$ & $11.5300 \mathrm{n}$ & -138.9805 \\
4 & $29.2000 \mathrm{k}$ & $37.8081 \mathrm{n}$ & -53.1517 \\
5 & $36.5000 \mathrm{k}$ & $35.5359 \mathrm{n}$ & -162.9730 \\
6 & $43.8000 \mathrm{k}$ & $20.2288 \mathrm{n}$ & -73.4323 \\
7 & $51.1000 \mathrm{k}$ & $14.2831 \mathrm{n}$ & 143.9914 \\
8 & $58.4000 \mathrm{k}$ & $4.6312 \mathrm{n}$ & 177.5460 \\
9 & $65.7000 \mathrm{k}$ & $4.5120 \mathrm{n}$ & 51.6697 \\
\hline \multicolumn{4}{c}{ dc component $=5.725 \mathrm{D}-06$} \\
\hline \multicolumn{4}{c}{ Total harmonic distortion $=1.0327$ percent } \\
\hline \multicolumn{4}{c}{}
\end{tabular}

\section{Conclusion}

In this paper, a new current-mode third-order quadrature oscillator using three CDTA and three grounded capacitors is proposed. Outputs of two sinusoids with $90^{\circ}$ phase difference are available in the proposed quadrature oscillator. The oscillation condition and oscillation frequency of the proposed quadrature oscillator are orthogonal controllable. Simulation results verify the theoretical analysis.

\section{Acknowledgments}

The author would like to thank the reviewers for their suggestions. The National Science Council, China, supported this work under Grant no. NSC 98-2221-E-033-054.

\section{References}

[1] A. S. Sedra and K. C. Smith, Microelectronic Circuits, Oxford University Press, New York, NY, USA, 4th edition, 1998.

[2] I. A. Khan and S. Khwaja, "An integrable gm-C quadrature oscillator," International Journal of Electronics, vol. 87, no. 11, pp. 1353-1357, 2000.

[3] R. Holzel, "Simple wide-band sine wave quadrature oscillator," IEEE Transactions on Instrumentation and Measurement, vol. 42, no. 3, pp. 758-760, 1993. 
[4] M. T. Ahmed, I. A. Khan, and N. Minhaj, "On transconductance-C quadrature oscillators," International Journal of Electronics, vol. 83, no. 2, pp. 201-207, 1997.

[5] M. T. Abuelma'atti and H. A. Alzaher, "Comment on currentmode quadrature sinusoidal oscillator using single FTFN," International Journal of Electronics, vol. 85, no. 2, pp. 177-180, 1998.

[6] A. M. Soliman, "Synthesis of grounded capacitor and grounded resistor oscillators," Journal of the Franklin Institute, vol. 336, no. 4, pp. 735-746, 1999.

[7] J.-W. Horng, "Current differencing buffered amplifiers based single resistance controlled quadrature oscillator employing grounded capacitors," IEICE Transactions on Fundamentals of Electronics, Communications and Computer Sciences, vol. E85A, no. 6, pp. 1416-1419, 2002.

[8] J.-W. Horng, "Current-mode quadrature oscillator with grounded capacitors and resistors using two DVCCs," IEICE Transactions on Fundamentals of Electronics, Communications and Computer Sciences, vol. E86-A, no. 8, pp. 2152-2154, 2003.

[9] P. Prommee and K. Dejhan, "An integrable electroniccontrolled quadrature sinusoidal oscillator using CMOS operational transconductance amplifier," International Journal of Electronics, vol. 89, no. 5, pp. 365-379, 2002.

[10] J.-W. Horng, C.-L. Hou, C.-M. Chang, W.-Y. Chung, H.-W. Tang, and Y.-H. Wen, "Quadrature oscillators using CCIIs," International Journal of Electronics, vol. 92, no. 1, pp. 21-31, 2005.

[11] J.-W. Horng, C.-L. Hou, C.-M. Chang, S.-W. Pan, J.-Y. Shie, and Y.-H. Wen, "Third-order quadrature oscillator with grounded capacitors using CCIIs," WSEAS Transactions on Electronics, vol. 4, no. 1, pp. 20-22, 2007.

[12] S. Maheshwari and I. A. Khan, "Current controlled third order quadrature oscillator," IEE Proceedings: Circuits, Devices of Systems, vol. 152, no. 6, pp. 605-607, 2005.

[13] J.-W. Horng, C.-L. Hou, C.-M. Chang, H.-P. Chou, C.-T. Lin, and Y.-H. Wen, "Quadrature oscillators with grounded capacitors and resistors using FDCCIIs," ETRI Journal, vol. 28, no. 4, pp. 486-494, 2006.

[14] J. W. Horng, C. L. Hou, C. M. Chang, S. T. Cheng, and H. Y. $\mathrm{Su}$, "Current or/and voltage-mode quadrature oscillators with grounded capacitors and resistors using FDCCIIs," WSEAS Transactions on Circuits and Systems, vol. 7, no. 3, pp. 129-138, 2008.

[15] A. U. Keskin, C. Aydin, E. Hancioglu, and C. Acar, "Quadrature oscillator using current differencing buffered amplifiers (CDBA)," Frequenz, vol. 60, no. 3-4, pp. 21-23, 2006.

[16] W. Tangsrirat and S. Pisitchalermpong, "CDBA-based quadrature sinusoidal oscillator," Frequenz, vol. 61, no. 3-4, pp. 102104, 2007.

[17] A. U. Keskin and D. Biolek, "Current mode quadrature oscillator using current differencing transconductance amplifiers (CDTA)," IEE Proceedings: Circuits, Devices \& Systems, vol. 153, no. 3, pp. 214-218, 2006.

[18] D. Biolek, "CDTA-Building block for current-mode analog signal processing," in Proceedings of the European Conference on Circuit Theory and Design (ECCTD '03), vol. 3, pp. 397400, Krakow, Poland, September 2003.

[19] A. U. Keskin, D. Biolek, E. Hancioglu, and V. Biolková, "Current-mode KHN filter employing current differencing transconductance amplifiers," AEU-International Journal of Electronics and Communications, vol. 60, no. 6, pp. 443-446, 2006.
[20] W. Tangsrirat and W. Tanjaroen, "Current-mode multiphase sinusoidal oscillator using current differencing transconductance amplifiers," Circuits, Systems, and Signal Processing, vol. 27, no. 1, pp. 81-93, 2008.

[21] D. Biolek, V. Biolkova, and A. U. Keskin, "Current mode quadrature oscillator using two CDTAs and two grounded capacitors," in Proceedings of the 5th International Conference on System Science and Simulation in Engineering (WSEAS '06), pp. 368-370, Tenerife, Spain, December 2006.

[22] M. Bhusan and R. W. Newcomb, "Grounding of capacitors in integrated circuits," Electronic Letters, vol. 3, no. 4, pp. 148149, 1967.

[23] A. Fabre, O. Saaid, and H. Barthelemy, "On the frequency limitations of the circuits based on second generation current conveyors," Analog Integrated Circuits and Signal Processing, vol. 7, no. 2, pp. 113-129, 1995. 

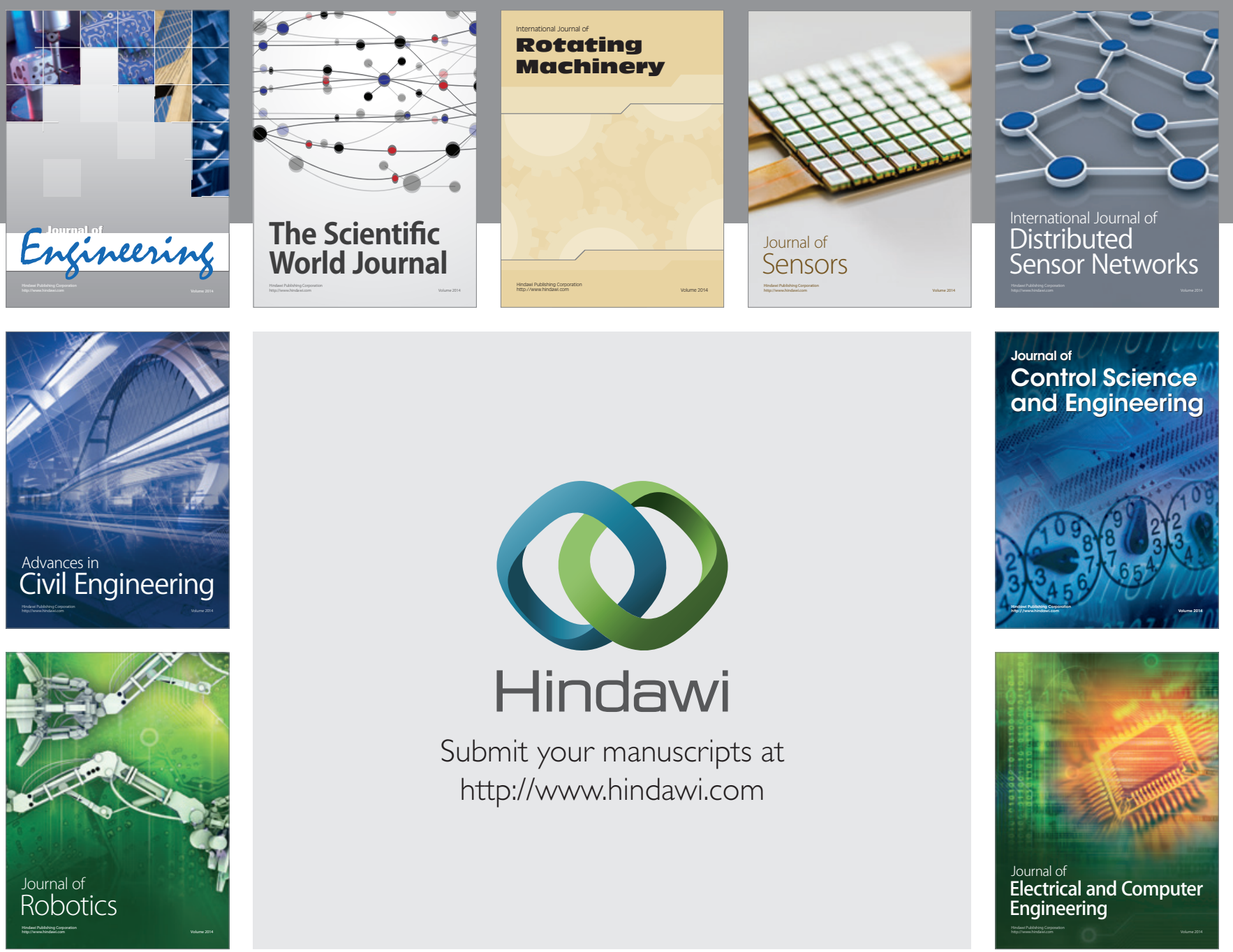

Submit your manuscripts at

http://www.hindawi.com
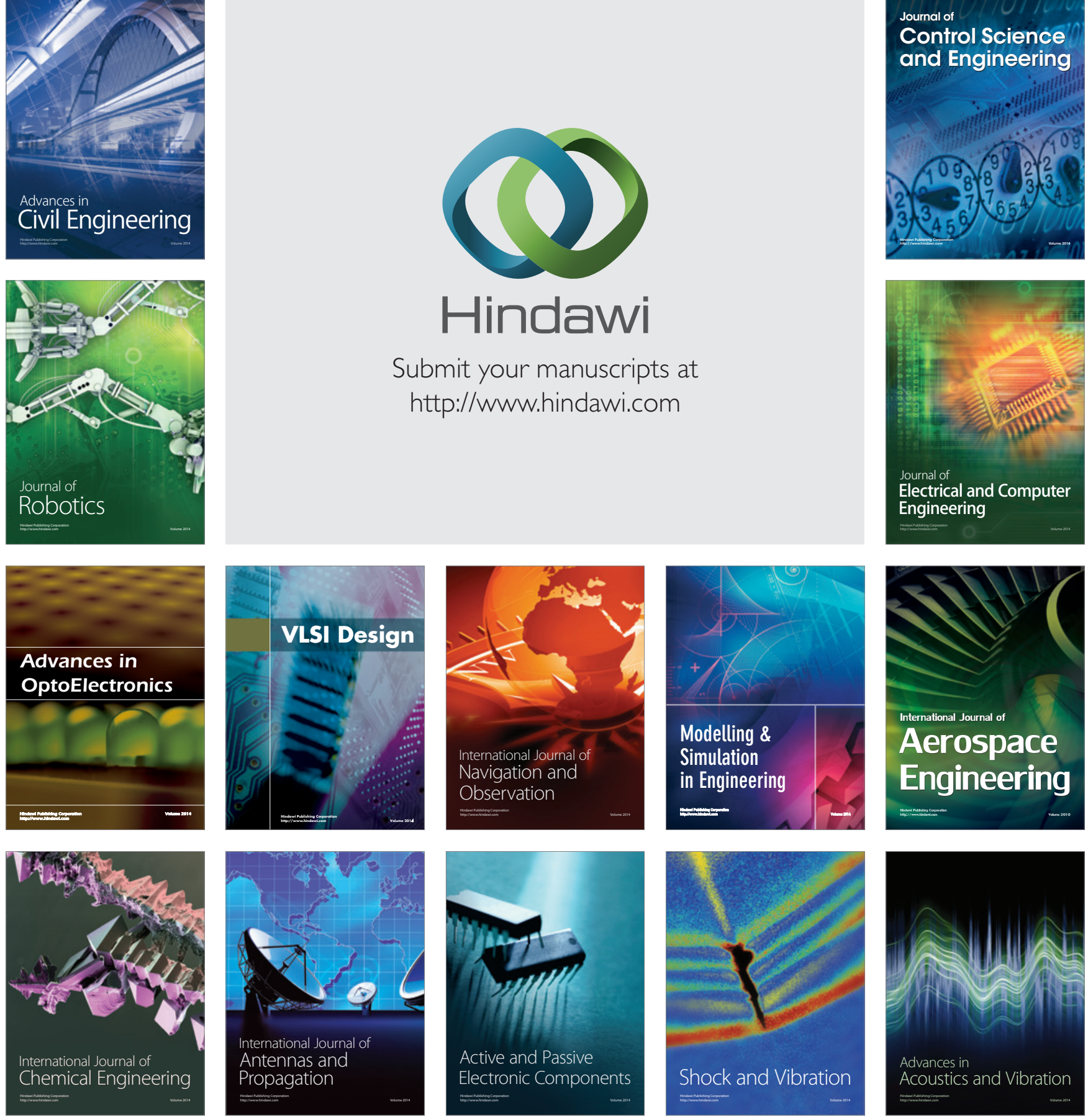